\title{
Poor maternal outcomes
}

To the Editor: I was surprised to read that Schoon and Motlolometsi were not able to find any clear job description or scope of practice for advanced midwives (ADMs) in this country. ${ }^{1}$ Both were clearly defined in KwaZulu-Natal in 1980, when the first ADM training programme was established at King Edward VIII Hospital, Durban.

The programme was co-designed by the Nursing College and the Community Obstetrics Department of the University of Natal medical school. The starting points used were the needs then apparent in the province's maternity services and the framework of regulations governing the Advanced Diploma in Midwifery and Neonatal Science. The scope of practice and job description were further developed by DEPAM (the Decentralised Education Programme for Advanced Midwives), funded by the Kellogg Foundation, and the university Department of Nursing's postgraduate programme. Only competent midwives were selected for the course.

The skills base aimed at developing nurse practitioners who would be able to do the following, in co-operation with the medical staff:

- adequately assess the health status of antenatal, intrapartum and postnatal women, and their neonates

- manage patients attending the high-risk antenatal clinics for women with hypertension, multiple pregnancies, previous caesarean section, gestational diabetes, etc.

- manage these women in labour with the assistance of the medical staff

- provide excellent postnatal care to 6 weeks postpartum

- monitor the standard of obstetric care, including organising and running monthly perinatal mortality meetings, and offer feedback to the district staff regarding all referrals

- provide ongoing in-service education for all midwives in the hospital and its referring clinics, later using the Perinatal Education Programme (PEP) $)^{2}$ material

- locate and train traditional midwives to bring them into the care net

- act as facilitators in building a perinatal care team in the unit.

We followed the first graduates from the diploma course back to their hospitals in northern KZN in 1981, and helped them to apply their skills there. Many of these nurse practitioners faced resistance from nursing managers, but most medical officers in rural units were grateful for their help, and bought into the concept. At that time, the district hospital system was fully integrated, and the ADMs were able to move around from each district hospital to its clinics, supporting and upgrading midwives' skills.

The impact of these enthusiastic women with medical support was impressive. Regional perinatal mortality dropped from 46/1 000 to $25 / 1000$ and the maternal mortality rate fell to $107 / 100000$ in 1993 , in spite of political turmoil in the province.

Unfortunately, the lack of a career path in clinical nursing care meant that many ADMs were later 'promoted' to administrative posts. Their impact was also vastly reduced by the new Health Act, which replaced their passionate hands-on clinical leadership with cadre-deployment bureaucrats who have no direct responsibility for obstetric outcomes. 


\title{
CORRESPONDENCE
}

Therein lies a lesson for those wishing to improve the lot of mothers and babies in South Africa.

\author{
J V Larsen \\ Howick \\ jon.larsen@iuncapped.co.za \\ 1. Schoon, MG, Motlolometsi MWA. Poor maternal outcomes: a factor of poor professional systems \\ design. S Afr Med J 2012;102(10):784-786. [http://dx.doi.org/10.7196/SAMJ.6130] \\ 2. Woods DL, Theron GB. Addressing poor maternal and perinatal outcomes. S Afr Med J 2012;102(10):786. \\ [http://dx.doi.org/10.7196//AMJ.6126] \\ S Afr Med J 2013;103(1):6-7. DOI:10.7196/SAMJ.6476
}

